\title{
Towards Understanding the Influence of Nature Imagery in User Interface Design: A Review of the Literature
}

\author{
Ashlea Rendell \\ The University of Newcastle \\ Ashlea.Rendell@uon.edu.au
}

\author{
Marc T. P. Adam \\ The University of Newcastle \\ Marc.Adam@newcastle.edu.au
}

\author{
Ami Eidels \\ The University of Newcastle \\ Ami.Eidels@newcastle.edu.au
}

\begin{abstract}
Nature imagery is frequently employed as a design element to improve how users experience interactions with computerized artifacts such as websites and mobile apps. However, literature on the influence of such imagery on human perception and behavior is scant and highly fragmented. In this paper, we develop a theoretical framework that integrates the different pathways for how nature imagery embedded in user interface design may affect user perception and behavior. Building on this framework, we synthesize the results of existing literature on how humans perceive nature imagery and the potential cognitive, affective, and behavioral responses. By providing a concise overview of key theories and results of the extant literature, this study contributes to the knowledge base of (1) scholars who theorize on the impact of nature imagery on user perception and behavior and (2) systems designers who intend to utilize nature imagery in their user interfaces.
\end{abstract}

\section{Introduction}

The use of background imagery has emerged as a key design element for engendering an attractive 'storefront' appeal in the digital economy. As consumers often form intentions towards products in online channels based on image and visual appeal [23], the selection of background imagery in user interface (UI) designs is an increasingly important consideration for human-computer interactions (HCI) researchers and user experience (UX) design practitioners.

When selecting images, many organizations choose attractive nature landscapes as their UI backgrounds. For instance, technology giants Apple and Microsoft both offer default desktop images for their products with a focus on picturesque nature scenery. Similarly, organizations in the energy and travel sectors often utilize nature landscape imagery in UI and promotional designs $[14,33]$. However, despite this widespread use of nature imagery, only little research has explored its potential influence on user perception and behavior $[21,28]$. Apart from imitating other successful ecommerce platforms, there are few guidelines available for practitioners to refer to during the image selection and design process, as well as limited understanding of the types of user responses and behavioral outcomes these images may be used to target, thus limiting the knowledge base for HCI researchers and practitioners.

Further, the few studies that explored nature images in the context of user perception and behavior are highly fragmented, spanning across the fields of Information Systems, Marketing, Psychology, and Urban Planning. As a result, the literature lacks a unified understanding of the theoretical pathways for how nature imagery influences user perception and behavior in a digital environment. For example, though recent studies have begun to assess cognitive responses to animal imagery in UI designs (e.g. snakes, a small mammal [21, 28]), research in Information Systems (IS) generally focuses on aesthetic responses. In contrast, research in Marketing and Psychology puts a stronger emphasis on theories rooted in environmental psychology, exploring the cognitive [18], affective [37], and behavioral responses (e.g., [10, 36]) to nature imagery, which are rarely considered in HCI research.

The present paper addresses this gap by establishing the current state-of-the-art in research on the influence of nature imagery in UI design on user perception and behavior. We conducted a systematic literature review of experimental studies in Information Systems, Marketing, Psychology, and Urban Planning. Search terminology was extracted from four seminal publications by Joye [16], Kaplan and Kaplan [18], Ulrich [37], and Wilson [41]. ${ }^{1}$ To select appropriate

\footnotetext{
${ }^{1}$ The search string was: ("user interface" OR "user experience" OR "human-computer interaction" OR "computer-human interaction" OR "visual design" OR "website design" OR "green advertising") AND ("nature imagery" OR "virtual nature" OR "biophilia" OR "biophilic" OR "landscape aesthetic" OR "landscape preference" OR "nature scenery" OR "savanna hypothesis" OR "savanna landscape" OR "grassy landscape" OR "landscape design"). Literature was sourced via IEEE, Scopus, and Web of Science, including all journal articles, conference papers, books, and book chapters on this topic.
} 
research we defined the following selection criteria: papers with (1) empirical data, (2a) a manipulation of nature imagery (physically or virtually), or (2b) an application of theories pertaining to nature imagery (e.g., landscape-preference matrix [18]), and (3) measures of cognitive, affective, and/or behavioral outcomes. Further, as our aim was to investigate nature landscape imagery and commercial UI design, we excluded studies with (1) clinical populations, (2) nature imagery with humans or animals (e.g., [28]), and (3) negative responses to nature images such as biophobia (e.g., [21]).

The contributions of our study are threefold. First, we provide an overview of the key theories on the influence of nature imagery. Second, we synthesize a body of highly fragmented literature on the role of nature imagery in user perception and behavior, a topic with very limited attention in IS research. Third, we develop an integrative theoretical framework which captures the relationships between nature imagery, user cognition and affect, and behavioral outcomes. For IS researchers, this study offers a reference point for methodological considerations when investigating nature imagery in UI design, synthesizing the constructs and measurement techniques currently employed in cognate areas. UX practitioners will gain an understanding of the potential types of imagery that can be used to influence behavioral outcomes.

\section{Foundations on nature imagery}

The notion of Biophilia established by Edward O. Wilson posits that humans have an innate yearning to connect with other natural life forms for our own physical, emotional, and spiritual health [41]. This biological tendency to seek connections with nature is said to manifest in the creation of urban gardens and parks, nature-inspired architecture, interior design, and human fascination with nature photography [16]. Further, Biophilia has also been credited as a fundamental motivator in the re-emergence of the United States conservation movement of the 1970's [41]. While Wilson's original notion of Biophilia was motivated by natural landscape aesthetics more broadly, Roger S. Ulrich [37] introduced an evolutionary theory of Biophilia that specifically focuses on the affective mechanisms triggered in response to natural landscapes. In an alternative, and yet complementary, theory Rachel and Stephen Kaplan [18] also suggested Biophilia to be responsible for positive cognitive responses, such as the restoration of fatigued directed attention capacities. Each of these Biophilia response theories are pertinent to the present review and have implications for $\mathrm{HCI}$ design.
Emphasizing affective responses, Ulrich [37] adopted an evolutionary psychology approach in suggesting that humans experience an automatic reduction in sympathetic nervous system activity when they are exposed to specific components of the natural environment. Now known as Stress-Reduction Theory (SRT), Ulrich [37] elaborated that during the Pleistocene Epoch verdant, flowering vegetation and clear, calm flowing water acted as reliable indicators of food and hydration sources, and thus offered survival advantage if recognized as such. Similarly, visual depth of a scene also offered survival advantage, by allowing the detection of approaching threats and subsequent seeking of refuge [37]. As the ability to process these environmental cues efficiently was critical to human survival, Ulrich [37] suggested that humans developed domain-specific brain modules responsible for processing nature stimuli and triggering an 'automatic' relaxation of the sympathetic nervous system. This process is experienced as a decrease in arousal, and a corresponding increase in positive affect. Each of these affective responses is subjectively interpreted as a nature-loving, or Biophilic response.

Focusing instead on the cognitive implications of Biophilia, Kaplan and Kaplan [18] introduced Attention-Restoration Theory (ART). According to ART, human information processing requires voluntary control of attention (directed attention) to filter task necessary from unnecessary environmental information. As this cognitive capacity is finite, the depletion of directed attention resources results in cognitive fatigue, and a corresponding drop in other associated executive functions (e.g., memory). The inherent fascination humans have towards the natural environment effortlessly engages involuntary attention, which allows the recovery of directed attention [18]. As a result, Biophilic cognitive responses will be experienced as an increased ability to attend to and process information, as well as improved memory of information attended to [18], which are both also interpreted subjectively as Biophilic responses.

While SRT and ART focus on two different effects of Biophilia, it has been suggested that they may not be mutually exclusive, but rather describe complementary phenomena [3]. Despite attempts to integrate the two theories [20], research has continued to adopt either Ulrich's [37] affect focused SRT or Kaplan and Kaplan's [18] cognition focused ART. Additionally, the few IS studies developing on Biophilia have instead focused on visual aesthetics theories (i.e., the landscape-preference matrix [19], or fractal aesthetics [16]). These, however, leave little room for IS researchers to explore the cognitive and affective user responses beyond aesthetic responses. Hence, our aim is to develop an integrative framework that 


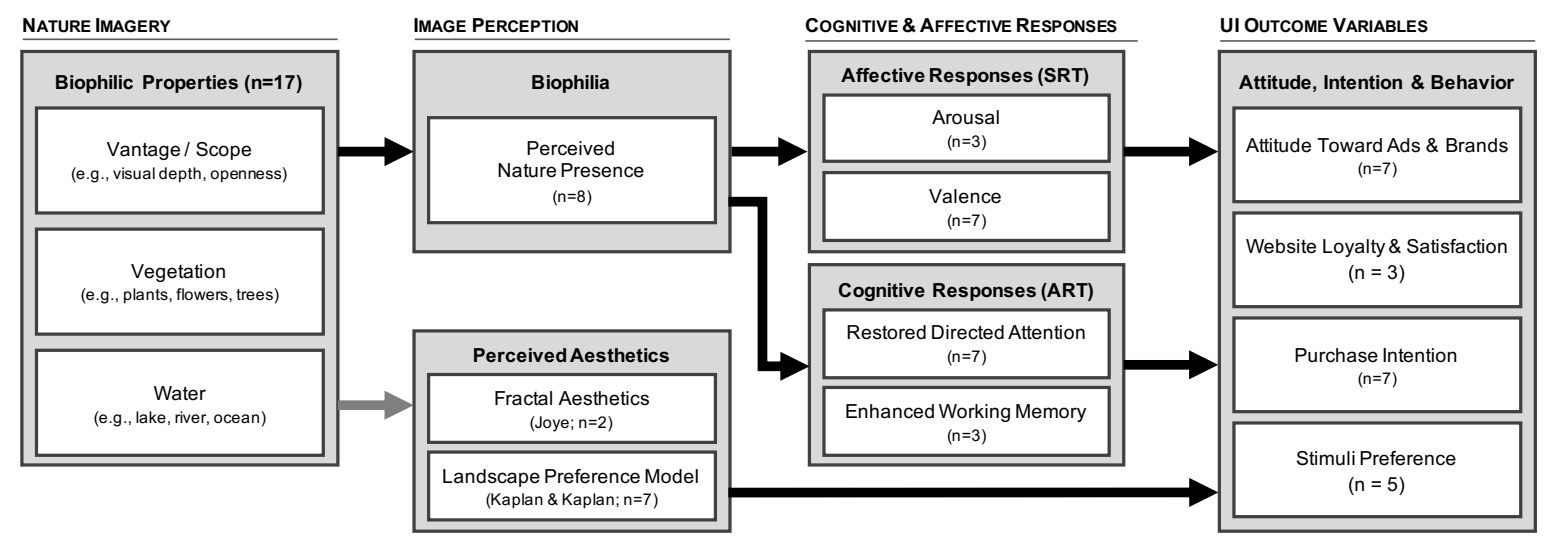

Figure 1. Theoretical framework on the influence of nature imagery on Ul outcome variables

incorporates the pathways associated with the affect focused SRT and the cognition focused ART, as well as an alternative pathway focusing on aesthetics.

\section{Integrative theoretical framework}

Our integration of ART and SRT, as well as the alternative aesthetics theories, can be seen in the theoretical framework in Figure 1. The image properties on the left are drawn primarily from SRT [37]. The quality and quantity of both visible water and vegetation, as well as the vantage of the scene are expected to have direct effects on the perceived nature presence of, and aesthetic responses to, a UI. The perceived nature presence construct conceptualizes a range of existing highly related concepts in the literature, namely perceived virtual nature experience $[12,32]$, perceived naturalness [9], perceived similarity to real nature [14], and perceived nature emotions congruency [11]. As described in Section 4.2 this construct denotes the perception of nature required within a UI to trigger the Biophilic affective and cognitive response targeted. The following response pathways reflect the affective responses of users as posited by SRT [37] and the cognitive responses as posited by ART [18]. Importantly, as detailed in Section 4.5, the UI outcome variables depicted in Figure 1 are only those that have emerged via the literature reviewed as dependent on the presence of nature imagery. It is recognized, however, that a range of other constructs pertaining to UI outcome variables have been explored extensively in relation to UI design (e.g., flow [29], trust [6], social presence [7], perceived ease of use [35], and perceived usefulness [38]) and while not explored in the present review are important outcome variables to be considered in future $\mathrm{HCI}$ research exploring the use of nature imagery.

Our framework also acknowledges the alternative theories, as depicted via the Perceived Aesthetics pathway. The critical difference between this and the Biophilia pathway is that the contributing aesthetics theories (i.e., landscape-preference matrix [18], fractal aesthetics [16]) do not consider the influence that specific natural elements (e.g., water, vegetation, vantage) have on user affect and cognition, but rather focus on structural components of the environment which can be assessed or applied independently of nature elements. The earlier landscape-preference matrix [19] was used as the foundation for ART. However, much of the IS literature has continued to adopt it as the paradigm of choice when investigating user responses to UI design. The landscape-preference matrix identifies Coherence, Complexity, Legibility, and Mystery as critical environmental elements for triggering positive aesthetic responses [19], yet these elements can be assessed independently of the image content and do not necessitate consideration of user cognition or affect (as detailed in Section 4.3).

Similarly, the notion of Fractal Aesthetics [16] suggests that rather than the water, vegetation, or vantage of a scene, it is the underlying geometric properties which influence the viewer's aesthetic response. These geometric properties, or fractals, can be calculated for any nature scene or otherwise, and thus can also be varied and assessed independently of nature elements. Each of these alternative theories thus focus on the structural properties of a scene, or image, rather than the nature content, and also focus on user aesthetic response rather than cognition or affect.

Despite this, aesthetic responses have been established as important mediators to UI outcome variables in existing HCI research (e.g., perceived ease of use [35], trust [2]), and there are also suggestions that aesthetic responses may be influenced by an individuals' information processing fluency (e.g., symmetry, contrast, and clarity can improve aesthetic judgements [27]). Hence, aesthetic responses are depicted as an alternative pathway in our framework. 


\section{Literature review}

Table 1 presents an overview of the 22 experimental studies that were included in the literature review. Due to limited IS research directly investigating nature imagery in UI design, the included literature covers ten studies from Marketing research, five studies from Psychology, four studies from Information Systems, and two studies from Urban Planning. While there are four studies from the IS field, as detailed in Section 4.3, they each adopt one of the alternative perceived aesthetics theories rather than ART or SRT. However, all four IS studies are an important contribution to understanding the current Biophilia approach within HCI research. In the following, we synthesize the results of the literature along the five main components of our framework.

\subsection{Nature elements}

Across the papers that directly assess nature elements $(n=17)$, the majority utilized photographs of nature landscapes $(\mathrm{n}=13$; one study utilized color slides [36] and has been grouped here as slides have been widely replaced by photographs). The other mediums include video footage $(\mathrm{n}=2)$, physical immersion in a nature environment $(\mathrm{n}=1)$, and specifically designed virtual environments $(n=1)$. The dominance of photographic stimuli increases the relevance of our review to the IS domain, in which interfaces exist digitally, often far removed from a physical nature environment. Within IS research (e.g., on IT-mediated business-to-consumer (B2C) sales), photographs are also currently the most likely medium for displaying environmental images in UI designs. In this respect, the experimental design of the surveyed studies offer a relevant context for IS research and practice.

A recent study by Thake and colleagues [34] identified six environmental elements as being critical for triggering Biophilic responses (water, vegetation, vantage, weather, protection, and access). Adopting an environmental psychology approach in line with SRT, Thake and colleagues created the Importance For Survival (IFS) scale, containing 16 items to identify the restoration potential of a nature image. However, it is notable that of the six elements assessed by the IFS, only three appear consistently in the literature: water, vegetation, and vantage are common visual components in all 17 studies we reviewed which assess nature imagery. Vegetation was explicitly mentioned in all but two studies, while 14 directly mentioned water present in their stimuli. Twelve of these studies also had consistent visible vantage requirements for the stimuli being used, such as photographs being taken from an approximate standing viewpoint with visibility reaching a defined distance into the scene.

In contrast, neither weather, protection, or access were explicitly defined image characteristics in any of the studies. Further, both protection and access are possibly by-products of adequate vantage, while inclement weather is unlikely to be used as imagery in promotional material for commercial UI designs. Finally, all 17 studies considered some combination of water, vegetation, and/or vantage, suggesting that there is an agreement in the literature that the image properties identified in our framework play an important role in triggering Biophilic responding.

\subsection{Perceived nature presence}

Eight papers contained items conceptualizing very similar constructs regarding user perceptions of nature. Overall, there appear to be two approaches to assessing user perceptions of nature: (1) four studies [5, 9, 11, 33] adopted the approach of having participants rate the degree to which the depicted environment is natural versus urban on a semantic differential scale, and subsequently assessed the relationship with user perception and behavior, while (2) three studies [12, $14,32]$ had participants rate the degree to which they associate nature experiences with the experimental artifact (primarily print advertising material) they were exposed to, and then assessed the relationship with subsequent outcomes. As there was a high degree of similarity between these definitions and items, they have been conceptualized into a single construct in our framework, that of Perceived Nature Presence.

Though there is some variety in the definition and items utilized to assess the construct of Perceived Nature Presence, all seven studies use some form of Likert-style agreement scales and are highly similar. For example, the construct 'virtual nature experience' was assessed by items such as "Brand $X$ evokes the sensation of being in nature" and "Brand $X$ makes me imagine nature, fields and forests" [12, 32], however, these same items were also used to assess the construct 'nature experiences' [14]. Similarly, a single 5-point Likert scale was used to assess both 'Naturalness' [9] ("How natural is the environment depicted in the view in your opinion?", not at all $=1>$ very much $=5$ ) and 'Environmental Context' [33] (totally natural environment $=1>$ totally built environment $=5$ ). As the virtual nature experience items used are highly aligned with social presence items [7] established in existing HCI research, the combination of these definitions and items provide an interesting opportunity for the future development of a perceived nature presence scale for HCI research. 
Table 1. Experimental studies on nature imagery and user responses

\begin{tabular}{|c|c|c|c|c|c|}
\hline \begin{tabular}{|l|}
$\begin{array}{l}\text { Ref \# } \\
\text { (discipline) }\end{array}$ \\
\end{tabular} & $\begin{array}{l}\text { Natural stimuli } \\
\text { (medium) }\end{array}$ & $\begin{array}{l}\text { Perceived nature } \\
\text { presence / aesthetics }\end{array}$ & Affect / cognition & $\begin{array}{l}\text { UI outcome } \\
\text { variables }\end{array}$ & $\begin{array}{c}\mathrm{N} \\
\text { (method) }\end{array}$ \\
\hline [11] (MKT) & Nature (video) & $\begin{array}{l}\text { NEC, degree of nature } \\
\text { (likert) }\end{array}$ & $\begin{array}{l}\text { Affect: valence (likert); } \\
\text { Cognition: memory (PAM) }\end{array}$ & $\begin{array}{l}\text { AAd, ABr, PI } \\
\text { (likert) }\end{array}$ & $\begin{array}{l}162 \text { (Srv.) } \\
160 \text { (Srv.) } \\
420 \text { (Srv.) }\end{array}$ \\
\hline $\begin{array}{l}{[34]} \\
(\mathrm{PSYC})\end{array}$ & $\begin{array}{l}\text { Water, } \\
\text { vegetation, } \\
\text { vantage (photo) }\end{array}$ & IFS & $\begin{array}{l}\text { Affect: 5x emotions, phys., } \\
\text { self-report (likert); Cognition } \\
\text { cognitive appraisals (likert) }\end{array}$ & $\begin{array}{l}\text { Preference } \\
\text { (Q-sort) }\end{array}$ & 40 (Exp.) \\
\hline [5] (PSYC) & $\begin{array}{l}\text { Vegetation, } \\
\text { vantage (photo) }\end{array}$ & $\begin{array}{l}\text { Degree of nature } \\
\text { (Q-sort), aesthetics } \\
\text { (spectral entropy) }\end{array}$ & $\begin{array}{l}\text { Cognition: attention } \\
\text { (phys.) }\end{array}$ & & 42 (Exp.) \\
\hline [33] (MKT) & $\begin{array}{l}\text { Water, vegetation } \\
\text { (photo) }\end{array}$ & $\begin{array}{l}\text { Degree of nature } \\
\text { (sem. diff.) }\end{array}$ & $\begin{array}{l}\text { Cognition: memory } \\
\text { (free recall) }\end{array}$ & $\begin{array}{l}\text { Preference } \\
\text { (likert, clickmap) }\end{array}$ & 331 (Exp.) \\
\hline [12] (MKT) & $\begin{array}{l}\text { Water, } \\
\text { vegetation, } \\
\text { vantage (photo) }\end{array}$ & $\begin{array}{l}\text { Virtual nature } \\
\text { experience (likert) }\end{array}$ & & $\mathrm{ABr}$ (likert) & 360 (Exp.) \\
\hline [32] (MKT) & $\begin{array}{l}\text { Water, } \\
\text { vegetation, } \\
\text { vantage (photo) }\end{array}$ & $\begin{array}{l}\text { Virtual nature } \\
\text { experience (likert) }\end{array}$ & & $\begin{array}{l}\mathrm{ABr} \text { (sem. diff.), } \\
\text { PI (likert) }\end{array}$ & 456 (Exp.) \\
\hline [14] (MKT) & $\begin{array}{l}\text { Water, } \\
\text { vegetation, } \\
\text { vantage (photo) }\end{array}$ & $\begin{array}{l}\text { Nature experiences } \\
\text { (likert) }\end{array}$ & & $\begin{array}{l}\text { ABr, PI, brand } \\
\text { benefits (likert) }\end{array}$ & 726 (Exp.) \\
\hline [9] (URB) & $\begin{array}{l}\text { Vegetation, } \\
\text { vantage (photo) }\end{array}$ & $\begin{array}{l}\text { Degree of nature } \\
\text { (likert) }\end{array}$ & & $\begin{array}{l}\text { Preference } \\
\text { (likert, select) }\end{array}$ & $\begin{array}{r}97 \text { (Exp.) } \\
4 \text { (Exp.) }\end{array}$ \\
\hline$[15](\mathrm{MKT})$ & $\begin{array}{l}\text { Water, } \\
\text { vegetation, } \\
\text { vantage (photo) }\end{array}$ & & $\begin{array}{l}\text { Affect: } 2 x \text { emotions } \\
\text { (sem. diff.) }\end{array}$ & AAd (likert) & 1057 (Еxp.) \\
\hline [13] (MKT) & $\begin{array}{l}\text { Water, } \\
\text { vegetation, } \\
\text { vantage (photo) }\end{array}$ & & $\begin{array}{l}\text { Affect: 6x emotions } \\
\text { (sem. diff.) }\end{array}$ & $\begin{array}{l}\text { AAd, } \mathrm{ABr} \\
\text { (likert), PI } \\
\text { (select) }\end{array}$ & 750 (Exp.) \\
\hline $\begin{array}{l}{[22]} \\
(\mathrm{PSYC})\end{array}$ & $\begin{array}{l}\text { Water, vegetation } \\
\text { (video) }\end{array}$ & & $\begin{array}{l}\text { Affect: arousal (phys.); } \\
\text { Cognition: attention (beh.) }\end{array}$ & & 28 (Exp.) \\
\hline (10] & $\begin{array}{l}\text { Water, } \\
\text { vegetation, } \\
\text { vantage (exp.) }\end{array}$ & & $\begin{array}{l}\text { Affect: } 2 x \text { emotions (likert, } \\
\text { ZIPERS), arousal (phys.); } \\
\text { Cognition: attention (beh.) }\end{array}$ & & $\begin{array}{l}68 \text { (Exp.) } \\
34 \text { (Exp.) }\end{array}$ \\
\hline [40] (MKT) & $\begin{array}{l}\text { Water, } \\
\text { vegetation, } \\
\text { vantage (photo) }\end{array}$ & & $\begin{array}{l}\text { Cognition: memory (beh.), } \\
\text { attention (phys.) }\end{array}$ & $\begin{array}{l}\text { Preference } \\
\text { (likert) }\end{array}$ & 30 (Exp.) \\
\hline$[26](\mathrm{MKT})$ & $\begin{array}{l}\text { Water, } \\
\text { vegetation, } \\
\text { vantage (photo) }\end{array}$ & & & $\begin{array}{l}\text { AAd, } \mathrm{ABr} \\
\text { (sem. diff.) }\end{array}$ & 484 (Exp.) \\
\hline $\begin{array}{l}{[36]} \\
(\mathrm{PSYC})\end{array}$ & $\begin{array}{l}\text { Water, vegetation } \\
\text { (colour slides) }\end{array}$ & Aesthetics (inf. rate) & $\begin{array}{l}\text { Affect: 4x emotions (sem. } \\
\text { diff.), arousal (phys.) }\end{array}$ & $\begin{array}{l}\text { Preference } \\
\text { (sem. diff.) }\end{array}$ & $\begin{array}{r}6 \text { (Exp.) } \\
18 \text { (Exp.) }\end{array}$ \\
\hline [17] & Virtual world & $\begin{array}{l}\text { Aesthetics } \\
\text { (fractal dim.) }\end{array}$ & Cognition: attention (beh.) & & 74 (Exp.) \\
\hline [39] (URB) & $\begin{array}{l}\text { Vegetation, } \\
\text { vantage (photo) }\end{array}$ & $\begin{array}{l}\text { Aesthetics (coh., } \\
\text { com., leg., mys.) }\end{array}$ & & Aesthetics (likert) & 100 (Exp.) \\
\hline [23] (IS) & & $\begin{array}{l}\text { Aesthetics (leg., mys., } \\
\text { coh.) }\end{array}$ & $\begin{array}{l}\text { Affect: } 3 x \text { emotions (sem. } \\
\text { diff.); Cognition: cognitive } \\
\text { appraisals (likert) }\end{array}$ & PI (likert) & 478 (Exp.) \\
\hline [42] (IS) & & $\begin{array}{l}\text { Aesthetics (coh., } \\
\text { leg., mys.) }\end{array}$ & & $\begin{array}{l}\text { PI, loyalty, } \\
\text { satisfaction } \\
\text { (likert) }\end{array}$ & 300 (Srv.) \\
\hline [24] (IS) & & $\begin{array}{l}\text { Aesthetics (coh., leg., } \\
\text { mys.) }\end{array}$ & & $\begin{array}{l}\text { Blog intent } \\
\text { (likert) }\end{array}$ & 280 (Srv.) \\
\hline [43] (MKT) & & $\begin{array}{l}\text { Aesthetics (coh., leg., } \\
\text { mys.) }\end{array}$ & & $\begin{array}{l}\text { Satisfaction, } \\
\text { loyalty (likert) }\end{array}$ & 170 (Srv.) \\
\hline [30] (IS) & & $\begin{array}{l}\text { Aesthetics (coh., } \\
\text { com., leg.) }\end{array}$ & & $\begin{array}{l}\text { Likelihood of } \\
\text { revisit }\end{array}$ & 211 (Srv.) \\
\hline
\end{tabular}




\subsection{Perceived aesthetics}

Nine of the 22 papers in our review focus on the perceived aesthetics pathway in our framework, four of which come from the IS domain. The most common approach was that of the landscape-preference matrix $(n=6)$. Coherence and Legibility were the only landscape-preference factors present in all six papers, Mystery appeared in five, and Complexity only appeared in two of the papers. Though the landscapepreference matrix was originally proposed as a predictor of preference regarding nature landscapes, these studies all adopt the matrix as a method of identifying how the aesthetic qualities of a UI (absent any nature imagery) will influence usability. In relation to the Fractal Aesthetics component of this pathway, one study calculated the spectral entropy of various landscapes and assessed their influence on viewer preference [5] and a second study assessed participant performance in a search task within virtual worlds specifically designed to vary according to their fractal dimensions (D) [17]. For example, a low complexity coastline (with no fine structure) would have $\mathrm{D}=1.0$ in comparison to a highly complex coastline (with a large volume of fine structure) with $\mathrm{D}=2.0$ [17].

Regardless of the adopted theoretical approach, all of the reviewed studies exploring the perceived aesthetics pathway found evidence supporting the notion that images, or visual artefacts such as websites, (1) scoring high in the landscape-preference matrix factors, or (2) with fractal dimensions within the range $1.0<\mathrm{D}<1.5$ [17], are likely to trigger more positive behavioral outcomes (e.g., website satisfaction) than those which do not. Separately, Reber and colleagues [27] have summarized empirical psychology research to suggest that the more fluently an individual can process an object the more positive their aesthetic response. For these reasons, the four IS papers reviewed and the associated aesthetic pathway appear important for IS researchers to consider when conducting future work in this area.

\subsection{Cognitive and affective responses}

The studies represented in the Perceived Aesthetics pathway do not consider the impact specific nature elements have on user cognition and affect, nor do they focus on the mediating role cognition and affect may play in UI outcome variables. While IS research traditionally focused primarily on usability and function, it is now acknowledged that a user's affective state in response to a UI is an important construct which has been traditionally overlooked [4]. Hence, there is an opportunity to build on the research within the
Perceived Aesthetics pathway by also considering the role of cognition and affect in this context.

4.4.1. Affective responses. Eight of the reviewed studies reported valence or arousal as indicators of affective responding. This conceptualization of affective responses aligns with Russell's circumplex model of affect [31], creating the distinction in our framework between the dimensions of arousal and valence in users' affective responses.

Across these eight studies, three reported on physiological measures of arousal, including blood pressure, heart rate, skin conductance, and alpha amplitudes. Ulrich [36] and Laumann and colleagues [22] both surmise that, in line with SRT, decreased heart rate in response to nature as compared to urban scenes support the notion of nature imagery triggering a relaxation process. Noting their non-significant results may be explained by the 10 minute delay between experimental manipulation and physiological measurements, Hartig and colleagues [10] on the other hand found no differences in blood pressure or heart rate. Further to this, Ulrich [36] presented evidence that alpha amplitudes, a measure of idle visual cortex activity and indicator of cognitive arousal (lower arousal is indicated by higher alpha amplitudes), were higher when participants were exposed to either vegetation or water scenes compared to urban scenes absent either natural element. This evidence directly supports the inclusion of the three image properties in our framework (water, vegetation, and vantage).

In contrast, six studies reported on the perceived valence of affective responses, using participant selfreport measures. The most common measurement tool in these studies were semantic differential scales where participants selected between a range of emotions, including happy/sad, anxious/relaxed, unsure/ confident, dull/exciting. Ulrich [36] originally reported that exposure to nature images specifically triggered a reduction in the experience of negatively-valenced affect (such as sadness, fear). Since then, all studies reviewed showed evidence of increased positive valence in response to nature images when compared to urban or neutral images. Hartmann and ApaolazaIbáñez [15] recognized that positive affective valence was more common in participants when exposed to nature images depicting both clear water and lush vegetation over desert and urban images alike, while Hartig and colleagues [10] also reported higher ratings of overall happiness (increased positive valence) and lower anger/aggression (decreased negative valence) responses in participants exposed to a nature setting. Overall, the body of research reporting on affective responses suggests both the increase of positively valenced affect as well as the decrease of negatively 
valenced affect in response to nature imagery should be explored in UI design.

It is important to note that while researchers have used neurophysiological measures to demonstrate the affective influences of Biophilia related imagery within UI designs, these studies used imagery focused on animals (e.g. snakes, small mammals) as well as contrasting positive and negative images (e.g. threatening wildlife compared to baby animals $[8,28])$ and so were not included in our review. This highlights an opportunity for HCI researchers to explore the neurophysiological indicators of user affect in response to UI designs containing nature imagery specifically.

In regards to potential mediating factors, Ulrich [36] found evidence of a stronger affective response to nature stimuli for females than males. As there have been no other indications of gender differences, a potential moderating role of gender on the influence of nature imagery may warrant further investigation.

4.4.2. Cognitive responses. Nine of the reviewed studies reported on participants' cognitive responses to different types of environmental stimuli. Within these nine studies all but one reported only a single measurement of cognition, assessing either attention $(n=4)$, memory $(n=2)$, or cognitive appraisal of the experimental stimuli $(\mathrm{n}=2)$. Only Wang and Sparks [40] reported measures of both attention and memory.

Two studies reported eye-tracking measurements as an indicator for participant attention, with Dupont et al. [5] and Wang and Sparks [40] both finding evidence of fewer, but longer fixations in participants viewing predominantly rural or nature landscapes compared to those viewing urban imagery. Despite similar outcomes, the interpretation of fixation data was slightly different between the two. Dupont et al. [5] suggested that more fixations and saccades for participants viewing urbanized landscapes indicates that less natural landscapes trigger more extensive visual search patterns, and thus higher attention or engagement with the scene. In contrast, Wang and Sparks [40] interpreted fewer, longer fixations in response to nature landscapes as evidence of a higher intrinsic attention for nature environments. Despite differences in the interpretation of these results, both studies indicate there is value in future IS research investigating eye-tracking data in response to UI designs containing nature images as their background.

An alternative measure of attention used in three studies $[10,17,22]$ is accuracy of performance on a cognitive task. Laumann and colleagues [22] utilized Posner's attention-orienting task while Hartig and colleagues [10] used a proofreading task, each to assess the recovery of directed attention capacity after exposure to either a nature or urban imagery. While
Laumann and colleagues [22] also consider response times on the task, both studies concluded that exposure to nature imagery facilitated cognitive restoration. This was evidenced by the absence of a validity effect [22] and by increased proof-reading accuracy [10] for participants in the nature conditions. Despite sitting within the perceived aesthetics pathway, Juliani and colleagues [17] also reported on attention, assessing participant performances in an environmental search task inside virtual environments designed to differ according to their fractal dimensions. They reported more accurate spatial judgements within the virtual landscapes with fractal dimensions between $1.1<\mathrm{D}<$ 1.5. Along with the other attention results reported, the results of Juliani and colleagues [17] add support for the cognitive response construct being an important pathway for IS research in this area.

The three studies exploring memory effects of nature imagery found evidence that participants had greater free-recall abilities for images containing nature imagery compared to those containing urban settings $[11,33,40]$. These findings offer an opportunity, as they suggest that when nature imagery is included in commercial UI designs there is the potential for increased user memory for the content delivered in the platform (e.g., knowledge management systems, product information websites). If so, this could offer advantages for organizations in the digital economy, whereby users may visit multiple websites or applications prior to making a product selection.

The study collecting cognitive appraisals focused on participants' perceived cognitive experience of interacting with an e-commerce website, using Likert scale items such as "I feel comfortable using the website to achieve my goals" [23]. Lee and Kozar [23] found positive influences of the UI on user perception, however adopted the landscape-preference matrix as their theoretical approach and thus fit within the perceived aesthetics pathway. Nevertheless, this also indicates the potential influence of user cognition on UI outcomes, and offers opportunity for IS researchers to assess user cognitive appraisals of UI designs containing nature imagery.

\subsection{User interface outcome variables}

Perhaps of most practical relevance to UI design are the behavioral outcomes which have thus far been assessed in response to nature imagery. In our review, only four studies did not assess a behavioral outcome that is applicable to the IS context, all of which come from the Psychology literature where physiological measures and cognitive capacity, memory, and/or eyetracking data are often the primary outcome variables of interest (see Section 4.4.2). 
The UI outcome variables reported across the reviewed literature include purchase intention $(n=7)$, attitudes towards advertisements and brands $(n=7)$, stimuli preference $(n=5)$, and website satisfaction and loyalty $(n=3)$. All outcome variables except for stimuli preference were assessed using Likert-type scales, though attitudes towards the advertisements and brands were assessed with a combination of agreement Likertscales and semantic differentials. Stimuli preference was assessed via a range of techniques, with one study employing the Q-sort method (participants sort images from most to least liked [34]), three studies using a Likert-scale of aesthetic judgement to infer preference across a set of images [9, 33, 40], and the final study using a semantic differential to assess aesthetic judgement as a proxy for image preference [36].

All seven studies assessing attitudes towards advertisements and brands come from the Marketing literature. Five of the seven studies were conducted by Hartmann and colleagues over a period of seven years [11-15], each reporting similar outcomes in relation to improved attitudes towards both the depicted brand and advertisement when the stimuli contained nature imagery. The other two studies also showed experimental advertisements for a product containing either nature image backgrounds or neutral backgrounds (along with other text-based stimuli) [26, 32]. These two studies found that the advertisements containing nature landscapes positively affected brand attitudes, which in turn positively influenced purchase intentions $[26,32]$. This group of findings support the notion that the inclusion of nature landscapes in commercial UI designs can positively affect user attitudes toward the subject organization and product.

The literature reviewed here assessing UI outcome variables has also established important metrics for the assessment of behavioral outcomes (purchase intention [23, 42], intention to continue blogging [25], and website loyalty [43]). Additionally, all of these studies reported positive influences of nature imagery on the outcomes assessed. It is important to note, however, that with the exception of a single recent paper [11], each of the seven studies in Marketing focused on the influence of nature imagery in the context of green or environmentally-friendly product advertising, introducing a potential confound for IS researchers. It has not yet been demonstrated that the influence of nature imagery within this work also applies to nongreen products, highlighting an area of opportunity for future HCI research on nature imagery.

\section{General discussion and future research}

As technology improves so too does the potential range of consumer choice, with increased access to more operating systems, online retailers, mobile applications, and digital products alike. This increase in the number of technology-mediated interactions places additional cognitive demands on users. They are increasingly multi-tasking across platforms, tasks, and devices, with the costs of task-switching and the inhibition of irrelevant actions or cognitions placing strain on executive attention [1]. As a result, organizations must explore and test new methods of engaging users with their UI designs to ensure longterm success in the digital economy. This increases the importance of getting embedded imagery and content right to avoid customers abandoning digital products.

UX teams are responsible for not only creating ideal user flows (e.g., through a sales UI), but also often for selecting the appropriate background imagery to convey brand and product identity, or trigger emotional connections with the product/brand/system in their users. Examples such as Microsoft's Windows Spotlight (a Windows 10 feature displaying a new image on the lock screen each day) demonstrate how UI designers already make use of nature imagery to positively influence user experience with their systems.

Our literature review brings together research on users' responses and behavioral outcomes motivated by the notion of Biophilia across a variety of research disciplines and study settings which may influence the use of nature imagery in the HCI context. Our study is the first to synthesize not only ART [18] and SRT [37], but also the alternative aesthetics focused explanations of the landscape-preference matrix [18] and fractal aesthetics [16] to understand the role of nature imagery in human perception and behavior. This framework may hence serve as a shared frame of reference for IS researchers and practitioners to simultaneously consider all four theoretical pathways in UI design.

Importantly, the review provides a concise overview of the constructs that have been explored in existing research on the role of nature imagery, as well as the most common and effective measurement approaches to guide and evaluate future research. Our review highlights opportunities for IS researchers to (1) identify the fractal dimensions which are conducive to fostering positive user responses to UI designs, (2) explore the use of neurophysiological measures of cognitive and affective user responses to UIs with embedded nature imagery, and (3) explore how user attention and memory are influenced by nature imagery within UI designs. In addition, we have identified opportunities to investigate whether the results of existing nature imagery research on eco-friendly products also apply to UI design more broadly (e.g., evendor websites of non-green products, or mobile health applications). To do so, IS researchers may also 
explore and validate the IFS scale [34] as a potential tool for selecting nature imagery for use in UI designs.

Finally, our review highlights a lack of qualitative investigation of user's Biophilic responding, and designers' Biophilic tendency towards nature imagery selection. Indeed, qualitative studies of user engagement outcomes may reveal further cognitive or affective responses which have not yet been considered. Further, interviews and focus groups with industry practitioners may help identify whether existing design practices for the selection of imagery and content align with our proposed framework of nature imagery in UI design.

Our framework also highlights opportunities for testing the impact of nature imagery in industry, by identifying the specific landscape characteristics that can be compared in different versions of the background imagery of a UI. UX practitioners may utilize the image properties conceptualized in our framework to identify various image types for use in live platform testing. In this vein, our framework provides industry practitioners with a visual frame of reference to understand the mechanisms through which their image selection may influence their users' perceptions and intended behavioral outcomes.

\section{Acknowledgements}

This research was supported by an Australian Government Research Training Program (RTP) Scholarship.

\section{References}

[1] R. A. Atchley, D. L. Strayer, and P. Atchley, "Creativity in the wild: Improving creative reasoning through immersion in natural settings.," PLoS ONE, vol. 7, no. 12, 2012.

[2] D. Cyr, M. Head, H. Larios, and B. Pan, "Exploring human images in website design: A multi-method approach," MIS Quarterly, vol. 33, no. 3, pp. 539-566, 2009.

[3] Y. A. W. de Kort, A. L. Meijnders, A. A. G. Sponselee, and W. A. Ijsselsteijn, "What's wrong with virtual trees? Restoring from stress in a mediated environment," Journal of Environmental Psychology, vol. 26, no. 4, pp. 309-320, 2006.

[4] A. Dillon, "Beyond usability: Process, outcome, and affect in human computer interactions," The Canadian Journal of Information and Library Science, vol. 26, no. 4, pp. 57-69, 2001.

[5] L. Dupont, K. Ooms, A. T. Duchowski, M. Antrop, and V. Van Eetvelde, "Investigating the visual exploration of the rural-urban gradient using eye-tracking," Spatial Cognition and Computation, vol. 17, no. 1-2, pp. 65-88, 2017.
[6] D. Gefen, E. Karahanna, and D. W. Straub, "Trust and TAM in online shopping: An integrated model," MIS Quarterly, vol. 27, no. 1, pp. 51-90, 2003.

[7] D. Gefen and D. W. Straub, "Managing user trust in B2C e-Services," e-Service Journal, vol. 2, no. 2, pp. 7-24, 2003.

[8] S. Gregor, A. C. H. Lin, T. Gedeon, A. Riaz, and D. Zhu, "Neuroscience and a nomological network for the understanding and assessment of emotions in information systems research," Journal of Management Information Systems, vol. 30, no. 4, pp. 13-48, 2014.

[9] K. Hansson, M. Külvik, S. Bell, and K. Maikov, "A preliminary assessment of preferences for Estonian natural forests," Baltic Forestry, vol. 18, no. 2, pp. 299-315, 2012.

[10] T. Hartig, M. Mang, and G. W. Evans, "Restorative effects of natural environment experiences," Environment and Behavior, vol. 23, no. 1, pp. 3-26, 1991.

[11] P. Hartmann, V. Apaolaza, and M. Eisend, "Nature imagery in non-green advertising: The effects of emotion, autobiographical memory, and consumer's green traits," Journal of Advertising, vol. 45, no. 4, pp. 427-440, 2016.

[12] P. Hartmann and V. Apaolaza-Ibáñez, "Green advertising revisited: Conditioning virtual nature experiences," International Journal of Advertising, vol. 28, no. 4, pp. 715-739, 2009.

[13] P. Hartmann and V. Apaolaza-Ibáñez, "Beyond savanna: An evolutionary and environmental psychology approach to behavioral effects of nature scenery in green advertising," Journal of Environmental Psychology, vol. 30, no. 1, pp. 119-128, 2010.

[14] P. Hartmann and V. Apaolaza-Ibáñez, "Consumer attitude and purchase intention toward green energy brands: The roles of psychological benefits and environmental concern," Journal of Business Research, vol. 65, no. 9, pp. 1254-1263, 2012.

[15] P. Hartmann and V. Apaolaza-Ibáñez, "Desert or rain: Standardisation of green advertising versus adaptation to the target audience's natural environment," European Journal of Marketing, vol. 47, no. 5-6, pp. 917-933, 2013.

[16] Y. Joye, "Architectural lessons from environmental psychology: The case of biophilic architecture," Review of General Psychology, vol. 11, no. 4, pp. 305-328, 2007.

[17] A. W. Juliani, A. J. Bies, C. R. Boydston, R. P. Taylor, and M. E. Sereno, "Navigation performance in virtual environments varies with fractal dimension of landscape," Journal of Environmental Psychology, vol. 47, pp. 155-165, 2016.

[18] R. Kaplan and S. Kaplan, The Experience of Nature: A Psychological Perspective. Cambridge: Cambridge University Press, 1989.

[19] S. Kaplan, "Aesthetics, affect, and cognition: Environmental preference from an evolutionary perspective," Environment and Behavior, vol. 19, no. 1, pp. 3-32, 1987. 
[20] S. Kaplan, "The restorative benefits of nature: Toward an integrative framework," Journal of Environmental Psychology, vol. 15, pp. 169-182, 1995.

[21] N. Kock, R. Chatelain-Jardon, and J. Carmona, "An experimental study of simulated web-based threats and their impact on knowledge communication effectiveness," IEEE Transactions on Professional Communication, vol. 51, no. 2, pp. 183-197, 2008.

[22] K. Laumann, T. Gärling, and K. M. Stormak, "Selective attention and heart rate responses to natural and urban environments," Journal of Environmental Psychology, vol. 23, no. 2, pp. 125-134, 2003.

[23] Y. Lee and K. A. Kozar, "Designing usable online stores: A landscape preference perspective," Information and Management, vol. 46, no. 1, pp. 31-41, 2009.

[24] Y. W. Liao and Y. S. Wang, "Investigating the influence of the landscape preference of blogs, user satisfactory and behavioral intention," Journal of Convergence Information Technology, vol. 6, no. 10, pp. 377-384, 2011.

[25] Y. W. Liao, Y. S. Wang, T. I. Tang, and Y. W. Tian, "Investigating the influence of the landscape preference of blogs, user satisfactory and behavioral intention," in Eighth International Conference on Information Technology: New Generations, 2011, pp. 833-838.

[26] J. Matthes, A. Wonneberger, and D. Schmuck, "Consumers' green involvement and the persuasive effects of emotional versus functional ads," Journal of Business Research, vol. 67, pp. 1885-1893, 2014.

[27] R. Reber, N. Schwarz, and P. Winkielman, "Processing fluency and aesthetic pleasure: Is beauty in the perceiver's processing experience?," Personality and Social Psychology Review, vol. 8, no. 4, pp. 364-382, 2004.

[28] A. Riaz, S. Gregor, and A. Lin, "Biophilia and biophobia in website design: Improving internet information dissemination," Information and Management, vol. 55, no. 2, pp. 199-214, 2018.

[29] R. Rissler, M. Nadj, M. T. P. Adam, and A. M. Maedche, "Towards an integrative theoretical framework of IT-mediated interruptions," in 25th European Conference on Information Systems (ECIS), Guimarães, Portugal, 2017, pp. 1950-1967.

[30] D. E. Rosen and E. Purinton, "Website design: Viewing the web as a cognitive landscape," Journal of Business Research, vol. 57, no. 7, pp. 787-794, 2004.

[31] J. A. Russell, "A circumplex model of affect," Journal of Personality and Social Psychology, vol. 39, no. 6, pp. 1161-1178, 1980.
[32] D. Schmuck, J. Matthes, B. Naderer, and M. Beaufort, "The effects of environmental brand attributes and nature imagery in green advertising," Environmental Communication, vol. 12, no. 3, pp. 414-429, 2018.

[33] B. A. Sparks and Y. Wang, "Natural and built photographic images: Preference, complexity, and recall," Journal of Travel and Tourism Marketing, vol. 31, no. 7, pp. 868-883, 2014.

[34] C. L. Thake, M. Bambling, S. Edirippulige, and E. Marx, "A psychoevolutionary approach to identifying preferred nature scenes with potential to provide restoration from stress," Health Environments Research and Design Journal, vol. 10, no. 5, pp. 111-124, 2017.

[35] N. Tractinsky, "Toward the study of aesthetics in information technology," in 25th International Conference on Information Systems, 2004, pp. 771-780.

[36] R. Ulrich, "Natural versus urban scenes: Some psychophysiological effects," Environment and Behavior, vol. 13 , no. 5, pp. 523-556, 1981.

[37] R. Ulrich, "Biophilia, biophobia, and natural landscapes," in The Biophilia Hypothesis, S. R. Kellert and E. O. Wilson, Eds. Washington, DC: Island Press, 1993, pp. 73-137.

[38] H. van der Heijden, "Factors influencing the usage of websites: The case of a generic portal in The Netherlands," Information \& Management, vol. 40, pp. 541-549, 2003.

[39] A. P. N. van der Jagt, T. Craig, J. Anable, M. J. Brewer, and D. G. Pearson, "Unearthing the picturesque: The validity of the preference matrix as a measure of landscape aesthetics," Landscape and Urban Planning, vol. 124, pp. 113, 2014.

[40] Y. Wang and B. A. Sparks, "An eye-tracking study of tourism photo stimuli: Image characteristics and ethnicity," Journal of Travel Research, vol. 55, no. 5, pp. 588-602, 2016.

[41] E. O. Wilson, Biophilia. Cambridge, Mass.: Harvard University Press, 1984.

[42] Y. S. Yeh and Y. M. Li, "Design-to-lure in the eshopping environment: A landscape preference approach," Information \& Management, vol. 51, no. 8, pp. 995-1004, 2014.

[43] D. Yüncü, "Relationships between perceptions of virtual destination environment, satisfaction and loyalty," Journal of Hospitality and Tourism Technology, vol. 6, no. 2, pp. 160173, 2015. 